\title{
M1-Anwender zu \\ Gast
}

Im Zuge der Abkündigung der M1-Ersatzteilversorgung, die Dentsply Sirona nunmehr 20 Jahren aufrechterhalten konnte, lädt das Unternehmen M1-Besitzer zu einer Kundeninformationsveranstaltung ein. Am „Tag der Einheit“ bietet das Unternehmen einen exklusiven Blick hinter die Kulissen und öffnet im Werk in Bensheim seine Tore. Unter dem Motto „Damals wie heute - einen Schritt voraus“ werden spannende Einblicke in die Produktion für moderne Behandlungseinheiten „Made in Germany“ geboten.

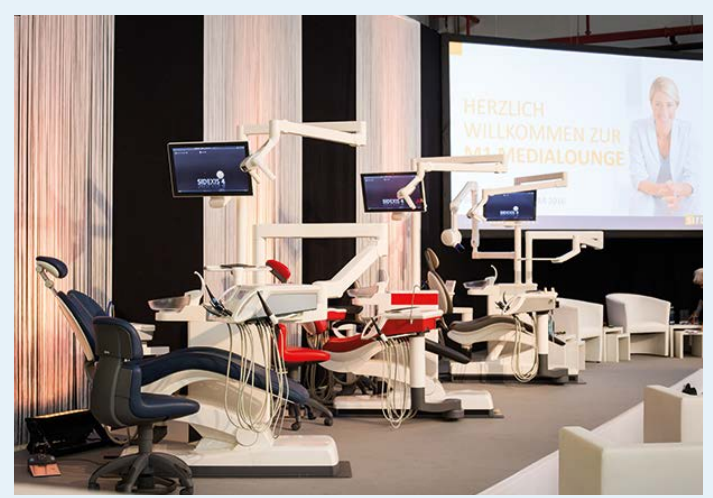

Wie die neue Generation der Behandlungseinheiten Arbeitsabläufe erleichtert, sich in den digitalen Workflow einbinden lässt und neueste Hygienestandards abbildet, das erfahren die Besucher im Showroom des Unternehmens. Ein Rückblick auf die Erfolgsgeschichte der M1 liefert spannende Hintergrundinformationen zur Entwicklung und kontinuierlichen Weiterentwicklung von Technologien. Zum Abschluss des „Tages der Einheit“ erwartet Interessenten an einer neuen Behandlungseinheit ein besonderes Highlight: Sie können sich einen TENEO oder eine SINIUS-Einheit ganz nach ihren Wünschen digital konfigurieren lassen und so testen, welche Features und Ausstattungen die Behandlungseinheit zu einem maßgeschneiderten Arbeitsplatz machen. Der „Tag der Einheit“ findet an 5 Terminen von April bis Juni in Bensheim statt. Weitere Informationen gibt es unter: www.danke-M1-hallo-zukunft.de.

Nach einer Pressemitteilung der

Sirona Dental GmbH, A - Wals bei Salzburg

www.sirona.com 